\title{
LA TRADUCCIÓN DE LOS ELEMENTOS FRASEOLÓGICOS EN EL DOBLAJE ITALIANO Y ESPAÑOL DE UNA SERIE POLICIACA NORTEAMERICANA. ESTUDIO DE CASO: NCIS Martina Tortato \\ Universidad de Málaga
}

\begin{abstract}
In the wide range of problems that translation offers, idioms play a relevant role and always cause misunderstandings and problems. This difficulty is amplified in the dubbing because this translation is bound to a series of restrictions and it must respect the original's time, image and space. In this article, we focus on the case study of idioms used in the American crime series NCIS. By comparing the original text to its Italian and Spanish dubbing, we draw conclusions about dubbing trends and techniques of the translation of idioms.
\end{abstract}

KEY WORDS: Dubbing, idioms, case study, Italian, Spanish, NCIS.

\section{RESUMEN}

En el gran abanico de dificultades que presenta la traducción, los enunciados fraseológicos desempeñan un papel muy relevante y siempre causan problemas de comprensión y traducción. Esto se amplifica en la traducción para el doblaje que está vinculada a una serie de restricciones y que tiene que respetar los tiempos, la imagen y los espacios del original. En este artículo, centramos nuestra atención en el estudio de caso de unos enunciados fraseológicos extraídos de la serie norteamericana de género policíaco NCIS. Mediante la comparación del texto original con las traducciones del doblaje italiano y español, sacamos unas conclusiones sobre las tendencias y las técnicas de traducción del doblaje de estos elementos en los dos países.

PALABRAS CLAVE: Doblaje, enunciados fraseológicos, estudio de caso, italiano, español, NCIS.

FECHA DE RECEPCIÓN: 09/02/2015

FECHA DE ACEPTACIÓN: 29/06/2015

PÁGINAS: 817-832 


\section{INTRODUCCIÓN}

En las últimas décadas hemos asistido a un creciente interés hacia el ámbito de la traducción audiovisual. Si al principio de los 80 se señalaba la ausencia de investigaciones y estudios sobre las traducciones para el doblaje y la subtitulación, hoy el campo está bastante desarrollado y se le presta casi la misma atención que a los otros tipos de traducción. Las investigaciones existentes se desarrollan tocando temáticas distintas y analizando elementos como:

1. Las características de los textos audiovisuales;

2. La metodología de estudio en este ámbito;

3. La historia de la TAV;

4. La relación entre TAV, ideología y censura;

5. Las relaciones entre el texto literario y su equivalente audiovisual;

6. Las técnicas de traducción;

7. El lenguaje del doblaje; el dubbese;

8. Los estudios de casos: comparación entre texto original (guión) y texto meta (doblaje y/o subtitulado);

9. La didáctica de la traducción para el doblaje (Chaume, 2012).

Dentro de estos enfoques, el que más éxito parece tener es el estudio de caso, que a su vez se centra en problemas y aspectos concretos como la traducción de las referencias culturales, del humor, de los juegos de palabras, de los modismos, de los nombres propios y de la variación lingüística. Estos elementos, entre otros, son los que más problemas traductólogicos proporcionan en la traducción en general y en la audiovisual en particular.

En este artículo acotamos aún más el tema para centrarnos en el análisis de las traducciones para el doblaje de elementos fraseológicos sacados de la serie norteamericana de género policiaco NCIS. Mediante el estudio de unos casos, analizaremos cómo se han traducido al italiano y al español unos elementos fraseológicos que resultan interesantes.

Nos hemos limitado a analizar el doblaje, y no el subtitulado, de esta serie por la importancia que el primero tiene en Italia y España ${ }^{1}$, por sus características y sus restricciones.

Ante todo, según la definición de Martínez Sierra (2004), la traducción audiovisual, y por tanto el doblaje, es:

${ }^{1}$ En estos países, el doblaje se ha impuesto como la modalidad preferida, y casi exclusiva, de traducción de películas y series extranjeras sobre todo por motivos económicos, políticos e ideológicos. Por esto, se ha desarrollado una tradición de doblaje de alta calidad al que el público está totalmente acostumbrado. 
una modalidad general de traducción que se ocupa de los textos audiovisuales, los cuales se caracterizan porque se transmiten a través de dos canales simultáneos y complementarios (el acústico y el visual) y por presentar una combinación, también simultánea y complementaria, de varios códigos de significación (lingüístico, paralingüístico, visual, etc.) cuyos signos interactúan y construyen el entramado semántico del texto audiovisual. Se trata de una variedad de traducción que presenta una serie de características propias que la definen frente a la traducción escrita y a la interpretación, y que tienen que ver principalmente con los condicionantes (internos y externos) que dicha modalidad presenta y las estrategias que requiere (2004:22).

Esta definición menciona algunas de las características del doblaje y llama la atención sobre los condicionantes de esta traducción: los límites y las restricciones que este medio impone. El traductor de doblaje necesita tener en cuenta los cincos tipos de sincronías señaladas por Mayoral, Kelly y Gallardo (1988): la temporal, la espacial, la de contenidos, la fonética y la de personaje. La traducción para el doblaje está sujeta a unos estrictos límites que obligan a simplificar el texto, reducir su duración y contenidos sin poderse alejar de la imagen que lo acompañan. Por estas limitaciones y la tipología textual a la que se aplica, podemos decir, a modo de definición, que el doblaje pretende sustituir una banda sonora con su equivalente más cercano, fiel y correcto en otro idioma, intentando respetar el diálogo original, el movimiento labial de los actores y las imágenes que se suceden en la pantalla. Por esto no se trata solo de una labor de traducción, sino de una adaptación y de un ajuste lingüístico, fonético, visual y cultural.

Hemos mencionado la importancia del doblaje en países como Italia y España que históricamente doblan todo lo que llega a sus pantallas y hacen que la difusión y la relevancia de esta traducción sea indudable. Es suficiente pensar en el papel del doblaje en la enseñanza del italiano a los italianos. Como afirman distintos estudiosos de la lengua ${ }^{2}$, el cine y la televisión han sido unos de los medios de comunicación más eficaces en la difusión y aprendizaje de un italiano estándar en un país fragmentado por los dialectos. Si pensamos en la multiplicidad de microlenguas presentes en el territorio y en la historia italiana, no tiene que extrañar la ausencia de un idioma uniforme difundido nacionalmente. La historia de la lengua italiana nace con la Divina Commedia de Dante Alighieri a principios del siglo XIV pero hasta el siglo XIX los dialectos se siguen usando en la mayoría de las situaciones de la vida cotidiana. Gracias a la

2 Entre otros, De Mauro (1993), Raffaelli (2004), Paolinelli y Di Fortunato (2005) y Rossi (2006). 
necesidad de darle voz, y una voz comprensible de norte a sur, a todas las películas que llegan a Italia, se elige la variedad del «fiorentino emendato, "epurato", privato di quei tratti, pur presenti anche nella pronuncia colta, riconosciuti come tipicamente caratteristici dell'area di provenienza ${ }^{3}$ 》 (Berruto, 1987: 58).

Se elige la forma dialectal del fiorentino, del cual viene el italiano de Dante, purificándolo de sus rasgos más dialectales para que sea modelo de un italiano estándar comprensible de norte a sur. Se favorece un idioma normalizado, correcto, formal y dominado por una pronunciación neutral (Paolinelli y Di Fortunato, 2005:13-14) que se insinúa en las casas y se impone como modelo de idioma nacional correcto y unitario.

Aunque en España el doblaje no tiene el mismo valor histórico, se señala la creación de lo que se suele definir como español neutro, es decir «an artificial dialect that combined features from the major Spanish dialects, particularly American localisms» (Chaume, 2012: 12). La elección de este idioma neutro, común a todos los países de habla hispánica, es sobre todo económica ya que, hasta los años 60 con un solo doblaje se exporta la misma película a numerosos países.

Otro elemento importante es la presencia de productos audiovisuales extranjeros en nuestros países: según el informe del European Audiovisual Observatory de 2001, más del 70\% de lo que se emite en la televisión española e italiana procede de Estados Unidos (Antonini, 2009).

Por las características del doblaje, por su difusión e importancia hemos limitado nuestro estudio a este tipo de traducción audiovisual y en concreto, hemos elegido un producto audiovisual de éxito y relevancia como NCIS. Se trata de la serie más vista en EE. UU. - con audiencia máxima de 22,86 millones de espectadores - que ha llegado a la duodécima temporada. Además, nos pareció interesante atrevernos con el análisis del doblaje de una serie que no pertenece al género de la comedia, al que ya se han dedicado muchos estudios, y dedicarnos a una serie policíaca que presenta un abanico de problemas de traducción aún más amplio que las comedias.

La serie trata de un equipo de agentes del NCIS, Naval Crime Investigative Service (servicio de investigación criminal de la Marina), que investiga casos relacionados con el personal de la Marina o del Ejército de Estados Unidos en el área de Washington. No obstante, el género de la investigación policíaca y detectivesca no es nuevo en el abanico de producciones americanas, NCIS nace en una década de oro para las series de este tipo y se diferencia de las demás porque «It's a combination of humor and suspense and action and pathos, and

3 «florentino enmendado, "depurado", privado de aquellos rasgos, que aun se manifiestan en la pronuncia culta, que se consideran característicos y representativos del área de procedencia» (la traducción es mía). 
all of these elements come together in a way that the other shows ... don't do» (en Chan, 2014: en línea).

Como ya hemos mencionado, la adaptación de una serie a otro idioma y a otra cultura plantea problemas que van más allá de los estrictamente translativos. Además de las limitaciones temporales, espaciales y labiales, hay que prestar atención a las imágenes y a los gestos de los personajes y a todo lo que ocurre en la pantalla. Por estos motivos, la adaptación resulta ser una difícil labor que requiere competencias lingüísticas, culturales y técnicas.

En el caso específico de NCIS, las dificultades son múltiples por la variedad de argumentos y tipologías textuales que encierra. Queda claro que, en primer lugar, el doblaje tiene que ofrecer al público un producto gramaticalmente correcto y natural, sin alejarse demasiado del original e intentando suscitar el mismo efecto en los espectadores que el producido en la versión en inglés. En NCIS, serie de investigación policíaca, encontramos diálogos muy técnicos y específicos, como ocurre en el caso de la especialista forense o del médico legal, que suelen utilizar un lenguaje científico que plantea problemas en la traducción de la terminología y en la corrección técnica. Además, hay que cuidar la forma de expresarse de los personajes en el texto original, en concreto, por lo que afecta a la adaptación. Hay que tener muy en cuenta, a este respecto, la forma de hablar típica de cada personaje: hay quien habla muy conciso y quien, por el contrario, habla muy rápidamente y con términos específicos, o quien no acierta con las expresiones idiomáticas inglesas $\mathrm{u}$ otros que recurren a chistes o frases de humor. Estos rasgos son elementos que hay que considerar a la hora de encontrar una traducción que se adapte a la imagen, a los tiempos y al movimiento labial.

Considerando la variedad del ámbito de la investigación en este campo, el objetivo de este artículo es analizar la traducción italiana y española del doblaje de algunos elementos fraseológicos que proporcionan problemas de traducción sobre todo si consideramos sus límites y sus restricciones.

\section{LOS ELEMENTOS FRASEOLÓGICOS Y EL DOBLAJE}

Los estudios sobre los elementos fraseológicos, o unidades fraseológicas, están bastante desarrollados, sobre todo gracias, entre otros expertos, al trabajo de la doctora Corpas, quien en su obra Manual de fraseología (1996) propone una clasificación precisa de estos elementos. En concreto los reparte en tres macrogrupos: colocaciones, locuciones y enunciados fraseológicos. Aunque la serie objeto de estudio presente todos estos elementos, los que han resultado más interesantes desde el punto de vista traductivo son los enunciados fraseológicos, es decir, todos aquellas 
construcciones inmutables de un idioma que han perdido su significado literal para adquirir otro que puede o no tener relación con el original. Además, estos elementos no suelen tener una traducción directa y lexicalmente parecida en otros idiomas. Un ejemplo podría ser la clásica expresión inglesa it's raining cats and dogs que pierde su significado literal de "llueven gatos y perros" para expresar el metafórico de "llover a cantaros". Como explica Umberto Eco en su Decir casi lo mismo: la traducción como experiencia (2008): "Sería un simple el traductor que, pensando que está diciendo lo mismo, lo tradujera literalmente como Llueven perros y gatos y no como Llueve a cántaros o Caen chuzos de punta» (Eco, 2008: 9).

Pero, ¿qué ocurre cuando esta expresión se utiliza en un producto audiovisual que tiene que ser doblado? Frente a las dificultades de encontrar una traducción fiel al original que mantenga los mismos matices, el traductor de doblaje tiene que negociar más de lo que negocia el traductor de una novela o de un artículo porque está sometido a las restricciones clásicas del doblaje, como las fonéticas, las temporales, las labiales y por última las visuales. Muy a menudo, los enunciados fraseológicos están entrelazados con las imágenes que se suceden en la pantalla y la dificultad se amplía. Un ejemplo concreto se puede encontrar en el doblaje de la famosa película de Disney Robin Hood (1973) en la que se emplea la expresión «to save [money] for a rainy day» con el significado de «to save money for a time when it might be needed unexpectedly» (Cambridge Dictionaries, en línea).

(TCR: 00:56:27)

[Hablando de una moneda]

- Oh, we were just saving it for a rainy day.

- Well, it's raining now.

En el contexto de uso resultan relevantes ambos significados del enunciado: el fraseológico, que indica un momento de necesidad y el literal, por la doble mención a la lluvia, mediante el comentario y la imagen de fondo de un día gris y de lluvia. Para un público anglófono la expresión se reitera y se reafirma al tener referencias visuales. Pero, ¿qué ocurre en el doblaje italiano y español? Las soluciones y las técnicas de traducción empleadas en los dos idiomas son casi opuestas, como se puede ver en los doblajes originales sacados obtenidos de las dos versiones.

- Bueno, lo estábamos guardando para una emergencia.

- Pues la emergencia ha llegado.

- Oh, noi lo conservavamo per un giorno di pioggia.

- Beh, ora sta piovendo. 
El doblaje español adapta a la lengua y a la cultura de llegada la expresión perdiendo el significado literal y figurativo y modificando la segunda línea explicitando todo el diálogo. Esta solución, para un público que no conoce la versión original, está perfectamente clara y no crea ninguna incomprensión o incoherencia entre lo visto y lo escuchado. Se pierde simplemente la relación con la lluvia como metáfora de dificultad económica que no forma parte de la cultura ni de la lengua española.

Sin embargo, el italiano mantiene esta expresión en su sentido literal e intenta mantener la relación entre lo dicho y lo visto, es decir, entre la expresión inglesa y la imagen de la lluvia. Para el público italiano que no tiene conocimientos del inglés, la oración en sí no tiene mucho sentido. ¿Por qué guardar una moneda para un día de lluvia? En italiano, un día de lluvia no conlleva los mismos significados que en inglés, y a lo mejor un niño, podría concluir que se guardaba la moneda para un día triste ya que la lluvia suele asociarse a la tristeza. Por otro lado, se mantiene la relación con la segunda expresión y con la imagen pero se importa en italiano una expresión que no se comprende totalmente y que confunde al espectador.

Este ejemplo, con las dos distintas traducciones, nos ayuda a comprender qué son los enunciados fraseológicos y cuáles son las dificultades que conlleva la traducción de estos elementos en el ámbito del doblaje. En ambos casos se ha perdido algo del original, en español la relación con la imagen de la lluvia y en italiano el verdadero significado de la línea. El traductor de doblaje tiene la difícil tarea de encontrar un compromiso entre fidelidad al texto origen y naturalidad de la lengua meta.

\section{ESTUDIO DE CASO}

Para el análisis hemos seleccionado 6 enunciados fraseológicos que nos parecen significativos y ejemplificativos:

1. Bun in the oven;

2. To be not someone's first rodeo;

3. Wink wink, nudge nudge y Bob's your uncle;

4. To be up a tree;

5. To look like you've seen a ghost;

6. To cover someone's bases.

Todos estos elementos, no presentan un equivalente directo y natural en las lenguas de llegada, por lo que tuvieron que ser adaptados o modificados 
para que fuesen comprensibles en las culturas metas. Las técnicas de traducción que se usan son varias según el caso y el idioma.

\subsection{CASO 1}

En el primer caso, el enunciado bun in the oven se presenta como una línea puesta en una camiseta que los personajes encuentran y de la que empiezan a hablar.

(s10e11 - TCR: 00:02:24)

[T- shirt: Bun in the Oven]

- I remember that case. That's the pregnancy pact.

En el original, el público inglés lee sin dificultad las letras en la pantalla y entiende su significado de «to be pregnant» (Cambridge Dictionaries, en línea) que conserva la imagen metafórica de la que nació, un bollo (el niño) que se cocina (crece) en un horno (el vientre materno). El problema se halla en la imposibilidad de cambiar la frase que aparece en la pantalla y por esto los doblajes italiano y español adoptan estrategias distintas.

\begin{tabular}{|l|l|}
\hline \multicolumn{1}{|c|}{ Italiano } & \multicolumn{1}{c|}{ Español } \\
\hline $\begin{array}{l}{[\varnothing]} \\
- \text { Ricordo quel caso. La tua finta } \\
\text { gravidanza. }\end{array}$ & $\begin{array}{l}\text { [Voz de fondo: Bollo en el horno] } \\
- \text { Recuerdo este caso. Es el conjunto de } \\
\text { embarazada. }\end{array}$ \\
\hline
\end{tabular}

En el primer caso, no se subtitula, ni se traduce de ninguna forma la expresión impidiendo la comprensión del público italiano que no entiende la segunda línea porque no se proporciona ninguna información al espectador.

Al contrario, en español una voz de fondo la traduce literalmente con bollo en el horno. Probablemente se comprenderá el sentido de la expresión por su uso en películas y series aunque no es una frase que forme parte del bagaje lingüístico y cultural de la audiencia meta.

Las técnicas de traducción empleadas son la omisión en el caso italiano y la traducción literal en el español. Sobre todo por lo que concierne el doblaje italiano, se habría podido proporcionar una traducción mediante los subtítulos bimbo a bordo (bebé a bordo) que aunque no sea el equivalente del original expresa el mismo sentido y da una pista al espectador italiano. Al mismo tiempo, se podría utilizar bebé a bordo en el doblaje español para evitar el calco del inglés. 


\subsection{CASO 2}

(s09e05 - TCR: 00:38:26)

- This isn't my first rodeo, Leon. Gibbs isn't my first cowboy.

La expresión this is not my first rodeo es muy típica de la habla inglesa y de la serie en general. Su primer significado está relacionado con el rodeo, es decir, «a public performance or competition in which cowboys $(=$ people who take care of cattle) show their skill at riding cattle and wild horses and at catching cattle with ropes» (Cambridge Dictionaries, en línea). Sin embargo, la expresión se ha convertido en elemento fraseológico porque se ha ampliado su campo de uso, que ahora abarca cualquier ámbito de la vida cotidiana, con objeto de expresar que alguien tiene experiencia previa en algún sector o aspecto de la vida.

En este caso, se quiere decir que ya se tiene experiencia en un ámbito muy concreto y se reitera esta afirmación, subrayando que Gibbs, el agente responsable, no es su first cowboy (primer vaquero).

En el doblaje español y en el italiano se ha traducido de forma literal las líneas aunque los equivalentes no sean expresiones típicas del italiano o del español.

\begin{tabular}{|l|c|}
\hline \multicolumn{1}{|c|}{ Italiano } & Español \\
\hline $\begin{array}{l}\text { Questo non è il mio primo rodeo, } \\
\text { Leon. E Gibbs non è il mio primo } \\
\text { cowboy. }\end{array}$ & Leon. Y Gibbs no es mi primer rodeo, \\
\hline
\end{tabular}

Es probable que, para una audiencia que conoce la lengua inglesa, la expresión suene perfectamente clara. Sin embargo, para los que no tienen estos conocimientos lingüísticos, la comprensión resulta un poco más difícil porque hay que apoyarse en su sentido literal. Al decir que no es la primera vez que se hace algo, se puede deducir que se tiene experiencia en un determinado campo. El hecho de que se especifique que se trata de un rodeo, puede confundir y extrañar pero, al final, la oración se comprenderá.

\subsection{CASO 3}

(s07e01 - TCR: 00:35:25)

Wow. You guys have a whole little thing going on that I'm not seeing. But I get it. Wink wink, nudge nudge. Bob's your uncle. 
En el diálogo citado se utilizan dos expresiones típicas del inglés coloquial que son bastante problemáticas: wink wink, nudge nudge y Bob's you're uncle. Según el Cambridge Dictionaries, wink wink (nudge nudge) tiene el significado de: «something you say when you want to suggest that there is a sexual meaning in something that has just been said» (en línea). La primera expresión, wink wink, procede de la verbalización del gesto: to wink es guiñar el ojo, mientras que to nudge es darle un codazo a alguien. Ambas acciones tienen el significado implícito de una complicidad entre las partes que no quieren o no pueden expresarse de forma clara. Al mismo tiempo, la expresión Bob's your uncle es un «satisfied suffix to a sentence meant to denote that the speaker's grasp of his subject is unimpeachable and no argument is necessary» (Bernstein, 2006) y «used to mean that something will happen very quickly and simply» (Cambridge Dictionaries, en línea). Como el elemento anterior, sirve para remarcar que se ha comprendido la alusión.

\begin{tabular}{|c|c|}
\hline Italiano & Español \\
\hline $\begin{array}{l}\text { Wow. Esigenze investigative. Non } \\
\text { sembrerebbe ma poi all'improvviso si } \\
\text { mettono in moto le rotelle nella } \\
\text { zucca e funzionano bene. }\end{array}$ & $\begin{array}{l}\text { Guau. Tenéis un montaje en marcha que } \\
\text { yo no veo pero lo capto. Un empujoncito } \\
\text { y todo arreglado, me va. Lo pillo. }\end{array}$ \\
\hline
\end{tabular}

En italiano se han adaptado los elementos ingleses mediante el uso de la oración mettere in moto le rotelle nella zucca, que indica que se entiende lo que se está diciendo mediante la imagen del cerebro (zucca) que funciona como una máquina con engranajes.

En español se juega con la traducción de la expresión anterior, tenéis un montaje en marcha (a little thing going on), para traducir las expresiones inglesas. Ya que se está hablando de algo que se pone en marcha, se utiliza la idea y práctica común de dar un golpe que puede que resuelva los problemas: un empujoncito $y$ todo arreglado.

Aunque las traducciones no sean fieles al original, se ha buscado expresar el sentido de todo el diálogo, es decir comprender algo que no se ha expresado de forma clara mediante una adaptación lingüística y cultural.

\subsection{CASO 4}

En este caso, la expresión objeto de análisis es to be up a tree (s06e24 TCR: 00:10:15) que, en su sentido fraseológico, significa encontrarse «in a difficult situation» (Heacock, 2003, 442). El diálogo se desarrolla jugando con el sentido literal y con el fraseológico del enunciado provocando un malentendido cómico. Además, la traducción está vinculada a las imágenes que la acompañan 
porque un agente está efectivamente subido a un árbol. La escena se desarrolla entre tres agentes: McGee, Di Nozzo y el agente de origen israelí Ziva David. McGee, que se encuentra en el despacho, intenta llamar a sus dos compañeros que están en la escena del crimen, pero solo Ziva contesta al teléfono. En ese momento, ella se encuentra subida a un árbol y desde allí se desarrolla la conversación telefónica con McGee y una conversación in vivo con DiNozzo, que está escuchando desde el suelo cerca del árbol y que solo se entera de lo que dice la agente David.

\begin{tabular}{|c|c|c|c|}
\hline & $\begin{array}{r}\text { Texto original } \\
\text { (inglés) }\end{array}$ & Italiano & Español \\
\hline McGee & $\begin{array}{l}\text { Hey, Gibbs wants you } \\
\text { guys to come back. }\end{array}$ & $\begin{array}{l}\text { - Hey, Gibbs dice che } \\
\text { dovete tornare. }\end{array}$ & $\begin{array}{l}\text { - ¡Hola! Gibbs quiere } \\
\text { que volváis. }\end{array}$ \\
\hline Ziva & - I'm up a tree. & $\begin{array}{l}\text { - Sono in cima a un } \\
\text { albero. }\end{array}$ & - Estoy colgada. \\
\hline McGee & $\begin{array}{l}\text { - Well, this might only } \\
\text { confuse you further. }\end{array}$ & $\begin{array}{l}\text { - Beh, cerca di non farti } \\
\text { male, ci servi intera. }\end{array}$ & $\begin{array}{l}\text { - Pues puede que aún te } \\
\text { confunda más. }\end{array}$ \\
\hline Ziva & $\begin{array}{l}\text { - Well, who said I was } \\
\text { confused? }\end{array}$ & $\begin{array}{l}\text { - Ti preoccupi per me } \\
\text { adesso? }\end{array}$ & $\begin{array}{l}\text { - ¿Quién ha dicho que } \\
\text { estoy confundida? }\end{array}$ \\
\hline McGee & $\begin{array}{l}\text { - You said you're up a } \\
\text { tree. }\end{array}$ & - Sbrigatevi a tornare. & $\begin{array}{l}\text { Dices que estás } \\
\text { colgada. }\end{array}$ \\
\hline Ziva & - I am. & - Va bene. & - Así es. \\
\hline Di Nozzo & $\begin{array}{l}\text { and not me? I'm the } \\
\text { senior field agent. }\end{array}$ & $\begin{array}{l}\text { chiamato me? Sono io } \\
\text { l'agente più anziano. }\end{array}$ & $\begin{array}{l}\text { no a mí? Tengo más } \\
\text { categoría. }\end{array}$ \\
\hline Ziva & $\begin{array}{l}\text { - I don't know why he's } \\
\text { not calling you, Tony. }\end{array}$ & $\begin{array}{l}\text { - Non lo so perché non } \\
\text { ha chiamato te, Tony. }\end{array}$ & $\begin{array}{l}\text { - No sé por qué no te } \\
\text { ha llamado a ti, Tony. }\end{array}$ \\
\hline McGee & - I did call Tony. & $\begin{array}{l}\text { - Ma ho chiamato } \\
\text { Tony. }\end{array}$ & - Sí, he llamado a Tony. \\
\hline Ziva & $\begin{array}{l}\text { - He's not making any } \\
\text { sense. }\end{array}$ & - Secondo n & $\begin{array}{l}\text { - Lo que dice no tiene } \\
\text { sentido. }\end{array}$ \\
\hline McGee & $\begin{array}{l}\text { And you're the one not } \\
\text { making sense. }\end{array}$ & $\begin{array}{l}\text { - Di a Tony che ho } \\
\text { provato a chiamarlo. }\end{array}$ & $\begin{array}{l}\text { - Lo que tú dices } \\
\text { tampoco lo tiene. }\end{array}$ \\
\hline Ziva & - He said he called you. & $\begin{array}{l}\text { - Dice che ha provato a } \\
\text { chiamarti prima. }\end{array}$ & $\begin{array}{l}\text { - Dice que te ha } \\
\text { llamado. }\end{array}$ \\
\hline Di Nozz & $\begin{array}{l}\text { - I'm not getting a } \\
\text { signal. How come } \\
\text { you're getting a signal } \\
\text { and I'm not? }\end{array}$ & $\begin{array}{l}\text { - Non ho campo. Come } \\
\text { mai il mio non } \\
\text { funziona e tu stai } \\
\text { parlando? }\end{array}$ & $\begin{array}{l}\text { - No tengo cobertura. } \\
\text { ¿Cómo es que tú sí } \\
\text { tienes y yo no? }\end{array}$ \\
\hline Ziv & - Because I'm up a tree. & $\begin{array}{l}\text { - Perché sono su un } \\
\text { albero }\end{array}$ & $\begin{array}{l}\text { - Porque estoy colgada } \\
\text { de un árbol. }\end{array}$ \\
\hline & - Oh. & - Ahh. & $-\mathrm{Ah}$ \\
\hline McGee & - Oh. & - Ahh. & - Ahhh. \\
\hline
\end{tabular}

El diálogo inglés se desarrolla a través de los distintos significados que los personajes le atribuyen a la expresión up a tree, creando un malentendido que solo se resuelve en el final. 
En la traducción italiana se mantiene la expresión en su sentido literal de estar subida a un árbol, essere su un albero, perdiendo el significado metafórico. Por este motivo, el diálogo cambia alejándose del texto original y, solo al final, vuelve al sentido original cuando se puede asociar el estar subido a un árbol con la cobertura en el móvil. En consecuencia, se pierde la ironía del texto original y el espectador italiano no puede disfrutar de esta escena porque no se ha encontrado una expresión con la que se pueda jugar como ocurre con el inglés. Una solución posible, aunque no perfecta, habría podido ser la alusión a stare tra le nuvole (estar entre las nubes) que en italiano conlleva un significado metafórico de «essere distratto» (Treccani, en línea) y que se podría utilizar ya que, al estar subido a un albero, uno se acerca al cielo y por esto a las nubes.

En español se juega con el adjetivo colgado, que puede tener el significado literal de «suspender, poner algo o a alguien sin que llegue al suelo» (DRAE, en línea) y también el metafórico de «contingente, incierto».

Ambos doblajes intentan adaptar a su lengua y a su cultura el enunciado fraseológico, sin embrago el español se mantiene más fiel al original mientras que el italiano tiene que modificar parte del diálogo para que todo tenga sentido.

\subsection{CASO 5}

(s04e20 - TCR: 00:07:35)

- McGee, you look like you've seen a goat.

- Ghost. Seen a ghost.

La expresión to look like/as though you've seen a ghost, como se puede intuir, significa «to look very shocked» (Cambridge Dictionaries, en línea). En el diálogo, el personaje, cuyo primer idioma no es el inglés, confunde el término ghost (fantasma) con goat (cabra) por su semejanza. El enunciado fraseológico original sufre una variación que tienen que mantenerse en los doblajes mediante una equivocación parecida.

\begin{tabular}{|l|l|}
\hline \multicolumn{1}{|c|}{ Italiano } & \multicolumn{1}{|c|}{ Español } \\
\hline $\begin{array}{l}\text { - McGee, chi dorme non prende il } \\
\text { pesce. }\end{array}$ & $\begin{array}{l}\text { - McGee, parece que haya visto un } \\
\text { electro. } \\
\text { - Pesci. Non prende pesci. }\end{array}$ \\
\hline
\end{tabular}

La traducción italiana prefiere cambiar totalmente la expresión idiomática por un proverbio muy conocido, chi dorme non piglia pesci, que no tiene el mismo significado que el original porque expresa que con la vida ociosa no se consigue nada. Se sustituye, sin motivo aparente una expresión por otra 
perdiendo el significado metafórico y el literal del original. Por esto, creemos que se habría podido modificar la expresión existente sembra che tu abbia visto un fantasma, traducción literal del inglés, que es conocida y utilizada aunque es probable que proceda de un calco del inglés.

En español se mantuvo la expresión inglesa: parece que haya visto un espectro, y se juega con la semejanza de las palabras espectro (fantasma) y electro. Se encuentra la expresión correspondiente al original y se adapta la equivocación, de modo que funcione del mismo modo del original.

\subsection{CASO 6}

(s03e18 - TCR: 00:13:05)

- We need eyes in that classroom.

- SRT snaked cameras through the vents. Here and here. Both were taped shut. Kody was covering his plates.

\section{- Bases.}

La expresión que se modifica a causa de un error es to cover one's bases, que tiene el mismo significado de cover all (the) bases, es decir: «to do everything necessary to be sure that something is successful» (Cambridge Dictionaries, en línea). Este elemento fraseológico procede del mundo deportivo y, en particular, del béisbol, donde para ganar puntos hay que ir tocando las bases del circuito. Como en el caso anterior, el personaje extranjero se confunde y utiliza plates en lugar de bases.

\begin{tabular}{|l|l|}
\hline \multicolumn{1}{|c|}{ Italiano } & \multicolumn{1}{|c|}{ Español } \\
\hline - Ci serve una visuale all'interno & - Necesitamos ojos en la clase. \\
dell'aula. & - Los artificieros colaron cámaras. Están \\
- Hanno infilato delle telecamere nelle & aquí y aquí. Las han precintado. Cody \\
prese d'aria. Qui e qui. Kody sa quello \\
che fa. Le ha sigillate col nastro adesivo. \\
- Guarda.
\end{tabular}

Para favorecer la comparación, y debido a que la adaptación italiana modifica el orden de las oraciones, tuvimos que ampliar el fragmento de texto analizado. Como se puede ver, el texto italiano ni presenta la modificación de la unidad fraseológica, ni respeta el orden de la oración inglesa. Ante todo cabe destacar que, en este doblaje, el personaje no se equivoca y el compañero no tiene que corregirlo. Para justificar esta línea se cambia el orden de la frase, de modo que el compañero pueda concordar y seguir con el discurso. 
En español se mantuvo el error mediante la asonancia entre bases y ases. Aunque, no nos parece que la expresión cubrir todas sus bases sea típica o utilizada en español.

En italiano, se uniforma el texto, eliminado tanto la equivocación como el uso del enunciado fraseológico. En español, se hace un calco del enunciado y se adapta el error al idioma.

\section{CONCLUSIONES}

Las estrategias de traducción que se emplean en los casos que hemos analizado son variadas y diferentes. Sin embargo, de este análisis podemos sacar unas conclusiones que habría que valorar en un estudio más amplio y completo. Lo que sí podemos observar son algunas tendencias en las técnicas traductivas: ante todo se puede notar que los traductores del doblaje tienen en cuenta las restricciones visuales que le impiden alejarse del sentido literal de los enunciados fraseológicos. En ambos idiomas y en aquellos casos en que la relación con las imágenes es significativa se utilizan estrategias de traducción como la literal y el calco. Estas traducciones generan frases que no son naturales ni típicas pero que permiten mantener la relación con el elemento visual. Como ya hemos mencionado, el sentido literal y muy a menudo metafórico de las expresiones permite la comprensión de las mismas y el espectador no se da cuenta de esta falta de naturalidad. En segunda instancia, destacamos unas tendencias en las adaptaciones llevadas a cabo en cada lengua. En el caso italiano se observa una preferencia hacia todas aquellas técnicas de traducción que acercan el texto al público meta, como la adaptación, la sustitución y la simplificación. Estas técnicas se aplican de un modo tal que el texto de llegada se aleja de su original y pierde matices importantes. Por el contrario, la versión doblada al español prefiere mantenerse fiel al texto original, importando en la lengua meta elementos lingüísticos y culturales que no son propios de su cultura. Por esto se utilizan técnicas como la adaptación, la traducción literal, la importación y los calcos.

Resumiendo:

\begin{tabular}{|l|c|c|}
\cline { 2 - 3 } \multicolumn{1}{c|}{} & $\begin{array}{c}\text { Técnicas de } \\
\text { traducción } \\
\text { al ITALIANO }\end{array}$ & $\begin{array}{c}\text { Técnicas de } \\
\text { traducción } \\
\text { al ESPANOL }\end{array}$ \\
\hline 1. bun in the oven & $\begin{array}{c}\text { Omisión } \\
\text { [No se traduce] }\end{array}$ & Calco/ T. Literal \\
\hline 2. to be not someone's first rodeo & Calco & Calco \\
\hline $\begin{array}{l}\text { 3. wink wink, nudge nudge } \\
\text { Bob's your uncle }\end{array}$ & $\begin{array}{c}\text { Adaptación } \\
\text { [Lejana del TO] }\end{array}$ & $\begin{array}{c}\text { Adaptación } \\
\text { [Cercana al TO] }\end{array}$ \\
\hline
\end{tabular}




\begin{tabular}{|l|c|c|}
\hline 4. to be up a tree & $\begin{array}{c}\text { Sustitución / } \\
\text { Adaptación }\end{array}$ & $\begin{array}{c}\text { Adaptación } \\
\text { [enunciado } \\
\text { fraseológico] }\end{array}$ \\
\hline 5. to look like you've seen a ghost & $\begin{array}{c}\text { Sustitución } \\
\text { [nmotivada] }\end{array}$ & Calco y Adaptación \\
\hline 6. to cover someone's bases & $\begin{array}{c}\text { Omisión } \\
\text { [Se modifica el TO] }\end{array}$ & Calco y Adaptación \\
\hline
\end{tabular}

Para decirlo con otros términos, el doblaje italiano tiende hacia la domesticación del texto, mientras que el español hacia una extranjerización. Sin embargo, si podemos decir que el italiano es más respetuoso y fiel a su idioma, la critica que se le suele hacer es que modifica y cambia el texto original.

Al contrario, en español, que mantiene más los matices y las características del texto original, se suele criticar la falta de respeto por la lengua española y por la importación de expresiones y palabras que no forman parte de su idioma y/o cultura.

El límite entre el respeto al texto original y el respeto a la lengua meta es muy borroso y la traducción para el doblaje, como otros tipos de traducción, busca constantemente el delicado y efímero equilibrio entre fidelidad al original y traducción natural, fluida y eficaz en la lengua y cultura meta. En conclusión, si los traductores, en general, tienen asignada la difícil tarea de recrear en otra lengua y en otra cultura un texto que conserve los mismos contenidos, colores y sabores del original, el traductor de doblaje tiene que hacerlo con unas restricciones que le impiden alejarse del producto original y lo obligan a encontrar un compromiso aunque ello conlleve perder algo.

\section{REFERENCIAS BIBLIOGRÁFICAS}

Antonini, Rachele (2009). «The perception of dubbed cultural references in Italy». En inTRAlinea, vol. 11. En línea: $<$ www.intralinea.org/archive/article/1651>.

Cambridge Dictionaries Online. En línea: < dictionary.cambridge.org>.

Chan, Vera (2013). «NCIS: The No. 1 TV Show That Nobody Talks About». En Yahoo TV. En línea:

$<$ tv.yahoo.com/news/-ncis---the-no--1-tv-show-that-nobody-talks-about212247183.html>.

Chaume, Frederic (2012). Audiovisual translation: Dubbing. Manchester, St. Jerome Publishing.

Corpas Pastor, Gloria (1996). Manual de fraseología española. Madrid, Gredos.

De Mauro, Tullio (2005). «Come parlano gli italiani». En Quaderns d'Italià, no. 10, 133-148. En línea: 
<www.raco.cat/index.php/QuadernsItalia/article/view/26334>.

DRAE. Diccionario de la Real Academia Española. En línea: <lema.rae.es/drae>.

Eco, Umberto (2008). Decir casi lo mismo: la traducción como experiencia. (Traducción de Helena Lozano Miralles). Barcelona, Lumen.

Heacock, Paul (2003). Cambridge Dictionary of American Idioms. Cambridge, Cambridge University Press.

Martínez Sierra, Juan José (2004). Estudio descriptvo y discursivo de la traducción del bumor en textos audiovisuales. El caso de Los Simpsons. Tesis doctoral. Disponible

en línea:<www.tdx.cat/bitstream/handle/10803/10566/martinez.pdf?sequenc $\mathrm{e}=1>$.

Mayoral, Roberto, Dorothy Kelly y Natividad Gallardo (1988). «Concept of constrained Translation. Non-Linguistic Perspective of Translation». En Meta: journal des traducteurs, vol. 33, no. 3, 356-367.

PAOlinelli, Mario y Eleonora Di FORTUnATO (2005): Tradurre per il doppiaggio. La trasposizione linguistica dell'audiovisivo: teoria e pratica di un'arte imperfetta. Milano, Ulrico Hoepli Editore.

Raffaelli, Sergio (2004): «L'italiano dei film doppiati» en Peron, Gianfelice (ed.): Premio Città di Monselice per la tradugione letteraria e scientifica. Monselice (Padua): Il Poligrafo, 63-73.

Rossi, Fabio (2006): "Il “doppiaggese"». En Il linguaggio cinematografico, Roma, Aracne editrice, 265-344.

Treccani Vocabolario. En línea: <www.treccani.it/vocabolario>. 